\title{
Serotonin and migraine: a reconsideration of the central theory
}

\author{
Alessandro Panconesi
}

Received: 26 June 2008/ Accepted: 11 July 2008/Published online: 31 July 2008

(C) Springer-Verlag 2008

\begin{abstract}
The 5-hydroxytryptamine (5-HT) has been implicated in migraine pathophysiology for the past 50 years. A low central 5-HT disposition associated with an increase in 5-HT release during attack is the most convincing change of 5-HT metabolism implicated in migraine. Peripheral studies on plasma/platelet have not generally shown low 5-HT levels. Studies on 5-HT reactivity showed hypersensitivity, also expressed as reduced tachyphylaxis (habituation), which successively was evidenced as the most characteristic marker of an altered sensory neurotransmission. Even the gender and seasonal variations of 5-HT parameters seem to agree with a low 5HT turnover with receptoral hypersensitivity. The interpretation of the effects of some serotonergic drugs and recent neuroimaging studies give major evidence for this cascade of events. Although the exact mechanism that links abnormal 5-HT neurotransmission to the manifestation of head pain has yet to be fully understood, a deficit on 5-HT descending pain inhibitory system is still probably today the most implicated in migraine pathophysiology. This short review focuses and discusses the alteration of peripheral and central 5-HT parameters in migraine patients.
\end{abstract}

Keywords Migraine $\cdot$ 5-Hydroxytryptamine . Gender differences $\cdot$ Seasons $\cdot 5$-HT release $\cdot$ Habituation

A. Panconesi $(\square)$

ASL 11, Empoli, Florence, Italy

e-mail: a.panconesi@virgilio.it

A. Panconesi

Via Amedeo Bassi 20, 50025 Montespertoli, Florence, Italy

\section{Introduction}

Thirteen years ago, concluding a revision on studies concerning the alterations of peripheral (platelets, vessels) serotonergic parameters in migraine patients I stated, "Why conduct any more research in the periphery?" [1]. In fact, further studies in plasma/platelet do not yield substantial new findings, while other vascular studies were not performed.

Since the first evidence from the Florence researchers of an altered metabolism of 5-hydroxytryptamine (5-HT), that is an increased urinary excretion of the 5-HT metabolite 5-hydroxyndoleacetic acid (5-HIAA) [2], the aim of studies on 5-HT was to show if migraine subjects have others modifications of 5-HT parameters. The original hypothesis of a deficiency of central 5-HT neurotransmission (empty neuron) as a biological marker of migraine subjects, with consequent 5-HT receptoral hypersensitivity $[3,4]$ is today discussed. In this light, the concept of 5-HT vulnerability, defined as increased sensitivity to natural or experimental alterations of the serotonergic system, proposed for depression [5] can be valid also for migraine.

Other than peripheral studies (platelets/vessels), the action of drugs affecting 5-HT central neurotransmission, that is, 5-HT selective reuptake inhibitors (SRRI), 5-HT releasers, 5-HT precursors, 5-HT receptor agonists, in migraine subjects was evaluated [6]. More recently, studies on possible genetic basis for altered 5-HT neurotransmission and neuroimaging studies on 5-HT metabolism were performed $[7,8]$.

The aim of this review is to critically evaluate studies concerning variations of 5-HT parameters, to try to define some data in order to avoid that further research is based on incorrect statements, which are frequently deduced from 
animal studies and therefore not completely transferable to humans.

Any research on possible alterations of central 5-HT neurotransmission (but also of other neurotransmitters) in migraine subjects must consider a few, but definite clinical remarks, which are evident to any headache specialist, as the clear prevalence in females and familiarity. Among the possible trigger factors, peri-menstrual period, the poststress weekend headache, the time immediately after an intense emotion/alarm/fear, alcoholic drinks, are those clearly associated with pain.

\section{Peripheral studies}

Platelets as a model of central 5-HT neurons, and then as the mirror of possible alterations of 5-HT neurotransmission in the brain, concerning the content, receptors and reuptake/transporter (SERT), were suggested and debated in the literature. Plasma 5-HT and 5-HIAA are also misleading since most plasma 5-HT is derived from the gut and less than $10 \%$ of 5-HIAA comes from the brain. Although no correlation was reported between midbrain and platelet SERT, recent single photon emission tomography (SPECT) evidence shows gender differences; that is SERT in midbrain are positively correlated with 5-HT uptake and negatively with 5-HT concentration of platelets, but only in females [9]. An hypothetical alteration of brain 5-HT neurotransmission in migraine patients, probably genetically determined, was repeatedly searched in the periphery (platelets, vessels, etc.), and sex and seasons were underlined as critical variables in the interpretation of diagnostic group differences $[1,10]$.

\section{Platelets}

Generally, it was stated that migraine patients have low platelet 5-HT, a sign of hyposerotonergic status of migraine. However, the vast majority of data show normal platelet and plasma 5-HT concentrations in migraine without aura both between attack and during pain in comparison with control subjects [11-25] (Table 1). Even the number of platelet 5-HT transporters (indirect indices of 5-HT reuptake) was normal in migraine and in chronic tension headache [26]. The release of 5-HT from platelet reported in some studies was probably non-specific and was considered not casually related to migraine attack [10, 27]. The finding of higher 5-HT platelet content in migraine with aura [18] was not confirmed [15, 21, 23]. Even in tension headache, platelet and plasma 5-HT are not decreased in headache-free period in comparison to control subjects [12-15, 19, 21, 28-34] (Table 2). Therefore, we can state that a hyposerotonergic status is not present in
Table 1 Comparative studies of platelet/plasma 5-HT levels between patients with migraine without aura in attack (In) and in attack-free period (Out) and control subjects

\begin{tabular}{|c|c|c|c|c|}
\hline \multirow[t]{2}{*}{ References } & \multicolumn{2}{|c|}{ Platelets } & \multicolumn{2}{|c|}{ Plasma } \\
\hline & Out & In & Out & In \\
\hline Waldenlinden [11] & $<$ & & & \\
\hline Shukla [12] & $=$ & & & \\
\hline Takeshima [13] & & & $>$ & \\
\hline Anthony [14] & $=$ & $=$ & & \\
\hline Ferrari [15] & $=$ & $<$ & $<$ & $=$ \\
\hline Nakano [16] & $=$ & & & \\
\hline D'Andrea [17] & $=$ & & & \\
\hline D'Andrea [18] & $=$ & & $=$ & \\
\hline Kitano [19] & & & $=$ & \\
\hline Srikiatkhachorn [20] & $=$ & & & \\
\hline Stronks [21] & $=$ & & $=$ & \\
\hline Evers [22] & $<$ & $<$ & $=$ & $=$ \\
\hline Jerney [23] & $=$ & $=$ & & \\
\hline Juhasz [24] & $<$ & & & \\
\hline Drummond [25] & $=$ & & & \\
\hline
\end{tabular}

Table 2 Comparative studies of platelet/plasma 5-HT levels between tension headache in attack (In) and in attack-free period $(O u t)$ with control subjects

\begin{tabular}{|c|c|c|c|c|}
\hline \multirow[t]{2}{*}{ References } & \multicolumn{2}{|c|}{ Platelets } & \multicolumn{2}{|c|}{ Plasma } \\
\hline & Out & In & Out & In \\
\hline Rolf [28] & & $<$ & & \\
\hline Shukla [12] & $=$ & & & \\
\hline Takeshima [13] & & & $>$ & \\
\hline Anthony [14] & & $<$ & & \\
\hline Ferrari [15] & & $=$ & & $=$ \\
\hline Shimomura [29] & & $<$ & & \\
\hline Leira [30] & & $>$ & & \\
\hline Kitano [19] & & & & $<$ \\
\hline Jensen [31] & & & $=$ & $>$ \\
\hline D'Andrea [32] & $>$ & & $>$ & \\
\hline Mazzotta [33] & $>$ & & & \\
\hline Bendtsen [34] & & $=$ & & $=$ \\
\hline Stronks [21] & $=$ & & $=$ & \\
\hline
\end{tabular}

migraine and tension headache patients in the periphery. The observed reduced platelet 5-HT in chronic migraine with or without medication overuse $[20,35,36]$ are not found in chronic tension headache [34].

\section{Vascular 5-HT reactivity}

The larger amount of studies on 5-HT vascular reactivity in migraine patients were performed in hand vein and 
previously reviewed [1]. From these studies three important findings deserve discussion: in fact they can be related to a possible 5-HT hypersensitivity provoked by hyposerotonergic state.

\section{Gender differences}

The evaluation of 5-HT reactivity in hand vein in a large sample shows that migraine subjects are more sensitive to controls. Moreover, female migraineurs are more sensitive than male migraineurs (Fig. 1). Higher 5-HT sensitivity in females was also found in other human vascular districts such as mammary and radial arteries [38, 39]. Interestingly, a heritable sexual dimorphism was described for whole blood 5-HT levels with higher level in women compared with men [40].

Important gender differences exist also in human brain 5-HT neurotransmission [41, 42], different to those with animal studies [43]. Studies of cerebrospinal fluid (CSF) concentrations of 5-HIAA, indirect indices of 5-HT synthesis and, by implication, of the transmitter for release into the synaptic cleft have yielded inconsistent results (see [42]). However, 5-HIAA reflects other processes in addition to 5-HT synthesis.

Validated positron emission tomography (PET) studies showed that men synthesize 5-HT significantly faster than women, and also with left-to-right differences [42, 44] even if an inverse finding was reported in a small study [45]. These gender differences are found in cortical regions but not in sub-cortical structures, including brainstem, where most 5-HT cell bodies are found [42]. Acute tryptophan depletion (ATP) causes a larger decrease in the rate of 5-HT synthesis in women [44]. It was affirmed that human males and females seem to have similar stores of brain 5-HT, but if there were increased utilization of 5-HT during stressful situations, a lower rate of synthesis in the

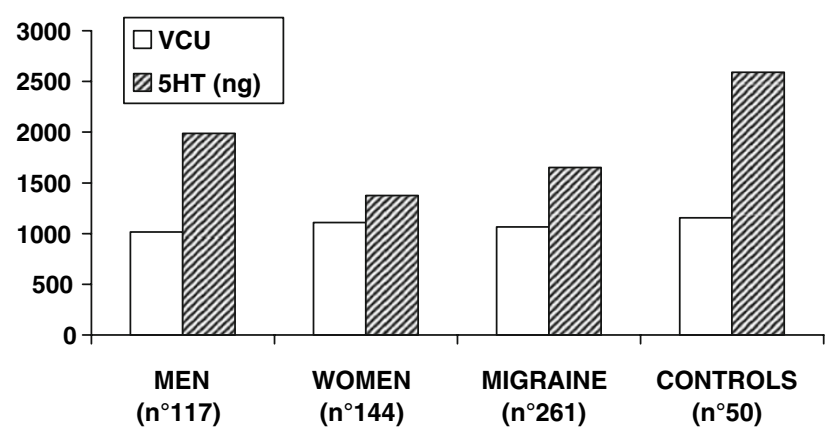

Fig. 1 5-HT reactivity in the hand vein expressed in venoconstriction units (VCU). Significant differences were found in the 5-HT doses eliciting roughly the same amount of contraction: migraine patients (examined in headache-free period) are more sensible (lower 5-HT dose) than controls $(P<0.001)$, migraine women are more sensible than migraine men $(P<0.001)$. Data from Panconesi et al. [37] females may not be as efficient in maintaining adequate stores of the neurotransmitter and then in such situations the 5-HT level would decline more in females [44]. Healthy women were reported to have higher 5-HT transporter availability in the diencephalon and brainstem compared to men. Since the 5-HT transporter functions to regulate 5-HT neurotransmission, these findings tend to suggest that baseline 5-HT functions may be higher in women versus men. Women have also higher number of 5$\mathrm{HT}_{1 \mathrm{~A}}$ receptors but not of $5-\mathrm{HT}_{2 \mathrm{~A}}$ : the latter are, however, increased by estrogens (see [41]). The greater (upregulation) $5-\mathrm{HT}_{1 \mathrm{~A}}$ bindings may be consequence of lower activity (synthesis) of serotonergic system (see [42]). Estrogens and estrogens + progesterone (that is the reproduction of the hormonal cycle of females) act on the gene and protein expression in dorsal raphe nucleus of nonhuman primates in a manner that suggests that 5-HT neurotransmission should increase: reduction of $5-\mathrm{HT}_{1 \mathrm{~A}}$, decrease 5-HT reuptake transporter (SERT), increase of tryptophan hydroxylase, MAO-A inhibition. The direct evidence of steroid-induced 5-HT release was sought with microdialysis [46].

\section{Seasonal variation}

The evaluation of seasonal changes in the vascular 5-HT hand vein reactivity clearly shows a lesser 5-HT sensitivity in the summer (Fig. 2). Many clinical studies, conducted in Italy and Austria, show that migraine frequency is lower in the summer in comparison to winter or autumn [47-52] (Table 3). Other studies do not concord [49, 50]. However, in one of these [50], when a bias was corrected, the seasonal differences disappeared, and even if real the seasonal effect is weaker. Also the reported higher attacks of migraine with aura (but not without aura) in the light season compared to the dark season in the arctic area became insignificant when insomnia-related attacks were removed [53]. In spite of this, in this latter study the peak frequency of migraine without aura was in December and the lowest frequency in June.

There are many evidences of increased content/turnover of 5-HT associated to decreased 5-HT receptor sensitivity

Table 3 Frequency of migraine attack by seasons

\begin{tabular}{lllll}
\hline References & Winter & Spring & Summer & Autumn \\
\hline Marrelli [47] & ++++ & +++ & + & ++ \\
Cugini [48] & ++++ & & + & \\
Robbins [49] & + & ++++ & ++ & +++ \\
Fox [50] & + & ++ & ++++ & +++ \\
Rieder [51] & & & + & ++++ \\
Soriani [52] & ++++ & & + & ++++ \\
\hline
\end{tabular}


in the brain, and also of plasma and platelet 5-HT content in the summer [1, 54].

The amount of 5-HT and its metabolites in the CSF are, at best, an imprecise indicator of brain serotonergic neuronal activity (synthesis). The measure of the differences between concentrations of neurotransmitters in the arteries and the internal jugular vein permit us to estimate the amounts produced in the brain. With this technique it was shown that in man, 5-HT turnover was lowest in winter and highest in summer, and was correlated to the bright sunlight of the day [55]. This finding was selective because extracerebral 5-HT turnover and also brain turnover of norepinephrine and dopamine did not show any seasonal variation. Another interesting preliminary finding is the reduced brain SERT availability in the winter compared to the summer [56].

\section{Habituation}

About 25 years ago, it was proved that migraine patients usually do not show tachyphylaxis (habituation) to the vasoconstrictive activity of 5-HT, different to control subjects [57].

Later on, the lack of habituation was thought to be the principal interictal abnormality in sensory processing in migraineurs, hypothesized due to hypofunction of 5-HT pathway to the thalamus and cortex [58-62]. Normalization of habituation during the attack was found [22, 63, 64] with a parallel decrease of platelet 5-HT [22]. According to Evers [22] the lack of significant association between the amount of habituation and platelet or plasma 5-HT suggested that the habituation phenomenon cannot be attributed to 5-HT neurotransmission; however, central 5-HT modification cannot be excluded.

Although the phenomenon of reduced habituation in migraineurs has been investigated mainly in the central nervous system, there are examples even in the peripheral system [65-67].

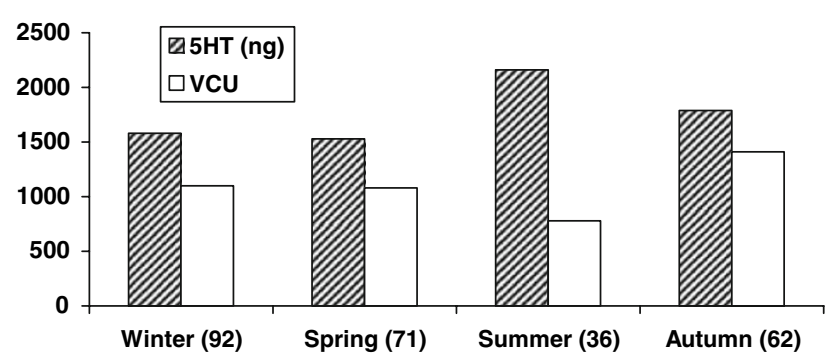

Fig. 2 Seasonal variations of 5-HT hand vein contraction, expressed in venoconstriction units (VCU), in a group of 261 migraine patients. In the summer higher 5-HT doses provoke a lesser amount of venoconstriction. From Panconesi et al. [37], modified

\section{Central studies}

Studies on the peripheral serotonergic system of migraineurs were often inconsistent, partly because of negative results, partly because of confounding factors, and their significance remains a matter of debate [1, 10]. Attempts toward an assessment of functional status of brain serotonergic system in migraineurs in vivo have been, until recently, possible only by the interpretation of mechanisms of action of some serotonergic drugs followed by measurement of their effects. There are few doubts that some 5-HT agonists can provoke a headache; what is in discussion is their mechanism [6]. Three major classes of 5-HT agonists exist: 5-HT releasing agents, 5-HT reuptake inhibitors (SSRI), 5-HT receptor agonists. Recently, methods for depletion of brain 5-HT and also neuroimaging studies to assess brain 5-HT level in vivo were applied to migraine.

\section{5-HT releasing agents}

\section{Reserpine and fenfluramine}

A single dose of reserpine will consistently induce headaches, closely resembling migraine, when administered intravenously, intramuscularly, or subcutaneously; but not or rarely in healthy controls [68]. Also fenfluramine provokes headache in more than $50 \%$ of migraine patients, with a mean latency of $4.5 \mathrm{~h}$, which was suggested to be due to 5-HT depletion, but not or less frequently in control subjects [65, 69]. However, the hypothesized 5-HT neuronal depletion as a mechanism of induced-headache apparently contrasts with some reports showing that chronic treatment with these two drugs, which probably provokes more depletion than acute treatment, and with the prototype of the depleting drugs p-chlorophenylalanine (PCPA), can have therapeutic effect on some migraine patients [69-71]. Fenfluramine challenge test administered to healthy subject (no migraine sufferers), provoked side effects in $90 \%$ of cases during the day, but more than half the following day: headache/migraine account of $43 \%$ of cases [72].

\section{m-Chlorophenylpiperazine $(m C P P)$}

The $5-\mathrm{HT}_{2 \mathrm{C}}$ receptor agonist $\mathrm{mCPP}$ is the most extensively used probe to show an altered serotonergic neurotransmission in migraine.

Brewerton et al. [73] reported that mCPP provoked severe headaches with migraine features $6-12 \mathrm{~h}$ after a single oral dose $(0.5 \mathrm{mg} / \mathrm{kg})$ in about $50 \%$ of female subjects. The incidence of headache was significantly greater in subjects with a personal or family history of migraine. Headache response following $\mathrm{mCPP}$ is greater 
in female patients with bulimia nervosa than control, irrespective of a personal or family history of migraine [74]. Another study tested on a few subjects, predominantly men, reported that $\mathrm{mCPP}(0.25 \mathrm{mg} / \mathrm{kg})$ induced headache in $50 \%$ of subjects, but without differences between migraine patients and controls, with a mean time onset of $5.3 \mathrm{~h} \mathrm{[75].} \mathrm{The} \mathrm{induction} \mathrm{of} \mathrm{migraine-like}$ headache in some subjects without personal history of migraine was also reported during pharmacokinetics studies, 5-10 h after oral administration [76]. However, that $\mathrm{mCPP}$ provokes more migraine (according to International Headache Society classification) than placebo and more likely in migraine patients than in controls was more recently confirmed [77].

The headache rating and duration was correlated with plasma peak concentration of mCPP occurring several hours earlier, and with the area under the curve (AUC), without differences between migraine and controls [73-75, 77], but no relation with plasma level was also reported [76]. Large inter-individual differences in mCPP pharmacokinetic parameters were shown [76, 78]. Interestingly, the AUC after oral administration varied more than 40fold, was threefold higher than intravenous administration, reached their peak after more than $3 \mathrm{~h}$, and could still be measured after $8 \mathrm{~h}$, and no differences were seen between male and females [76].

The fact that there were no differences in the cortisol response to $\mathrm{mCPP}$ between migraine patients and controls had led to the suggestion that $5-\mathrm{HT}_{2 \mathrm{C}}$ receptors are normal in migraine [75, 79]. Prolactin response was shown to be both normal [75] and increased [79]. The peak of these neuroendocrine responses was at 90-150 $\mathrm{min}$, and both correlation [75, 79], and non-correlation [78] with mCPP plasma concentrations were reported. Also some subjective side effects, other than headache, occur within $3 \mathrm{~h}$ [78]. The fact that hormonal response precedes the headache suggests that $\mathrm{mCPP}$ interaction with 5-HT receptors in the brain occurs initially in the cascade of events that ultimately results in headache [75], or that headache is not due to direct 5-HT receptor stimulation. Moreover, whether 5-HT receptor sensitivity is decreased or increased probably depends on the anatomical location of the pathway mediating the target response, and differential involvement of 5-HT receptor subtype. In fact, $\mathrm{mCPP}$ in addition to its 5-HT receptoral agonist activity is similar to fenfluramine, a potent 5-HT releaser [80]. This property should be taken into account for the similar time latency in the headache provocation shown by these two drugs.

However, for its adverse side effects and its variability of pharmacokinetic and of clinical and hormonal effects, $\mathrm{m}$-CCP was suggested to be an inadequate drug to carry out challenge tests to test receptor sensitivity in vivo [78].
Other 5-HT releasing drugs

The 3,4-methylenedioxymethamphetamine (MDMA/ecstasy) is an illicit drug that stimulates the release of 5-HT from neurons [80]. Although systematic studies have not been performed to show headache provocation, a comprehensive review of studies on the acute subjective effects of MDMA shows that not only headache, but also nausea and vomiting, is one of the more frequently reported somatic effects [81].

\section{Selective serotonin reuptake inhibitors (SSRI)}

Two good reviews show that SSRI have no therapeutic activity in migraine and tension headache [82, 83]. Moreover, the preventive effect of amitriptiline seems not due to 5-HT reuptake inhibition [84]. On the other hand, the headache is not a main side effect of SSRI reported in the headache treatment studies [6, 82]. Consequently 5-HT reuptake inhibition, differently by 5 -HT release or 5-HT receptor agonism, seems not to be important in the pathogenesis of headache. What is the reason?

The SSRI and 5-HT releasers both elevate extracellular concentration of transmitter via transporter-dependent mechanism, but with important differences (see [80]): (1) SSRI tends to produce small increases in extracellular neurotransmitter whereas releasers tend to produce robust increases as shown by in vivo microdialysis (2) Fenfluramine, norfenfluramine, mCPP and MDMA are potent 5-HT releasers via carried-mediated exchange mechanism involving SERT sites in the brain, (3) Fenfluramine and mCPP also have direct agonist actions at 5-HT receptors. Fenfluramine, especially their metabolite norfenfluramine, are potent $5-\mathrm{HT}_{2 \mathrm{C}}$ and $5-\mathrm{HT}_{2 \mathrm{~B}}$ receptor agonists, while $\mathrm{mCPP}$ is a very potent agonist in human $5-\mathrm{HT}_{2 \mathrm{C}}$ receptors and also at 5- $\mathrm{HT}_{1 \mathrm{~A}}$ [85]. One approach for discriminating presynaptic (i.e., 5-HT release) versus postsynaptic (i.e., 5HT receptor agonism) activities is pretreatment with SSRI which antagonize SERT and then the presynaptic effect of 5-HT releasers. Using this paradigm it was shown that anorectic action of fenfluramine is mediated at least in part by postsynaptic action. In this light, it would be of interest to see if $\mathrm{mCPP}$ is capable of provoking headache during SSRI treatment.

Another interesting finding was that high-doses of mCPP do not deplete 5-HT in the brain, and therapeutic doses of fenfluramine seem not to provoke depletion and then neurotoxicity [80].

\section{5-HT depletion}

Historically, methods to functionally deplete serotonin have been problematic and inapplicable to humans. Rapid 
tryptophan depletion (RTD) is a method that markedly diminishes plasma tryptophan and brain 5-HT synthesis and availability $[44,86]$, although there is evidence that it does not alter the efflux/release from neurons [87]. RTD as a method for studying 5-HT depletion is particularly suitable for subpopulations that show a vulnerability to 5-HT dysregulation. That is, those groups that show a reduced availability of central 5-HT are especially sensitive to RTD $[87,88]$. It was shown that RTD does not trigger full-blown migraine attack, even if it intensifies migrainous symptoms $[25,89]$.

\section{Neuroimaging studies}

Recently, neuroimaging studies demonstrated a significant increase of mesopontine brainstem (but not in the thalamus, the rostral relay station for nociceptive signals) SERT availability in headache-free migraine patients, a site which neuroimaging studies pointed to be specific for migraine pathophysiology. However, it remains to be elucidated as to whether it is causally related to migraine pathophysiology, or whether it reflects a chronic pain condition, that is, if it is the cause, or the consequence of migraine chronification [90]. Imaging methods to assess brain 5-HT level in vivo are lacking; however, a PET study on a small group of female migraine patients reported a global, non-regionspecific increase in the brain 5-HT synthesis capacity than female controls [91].

Different from this study, it was shown recently that in migraine patients the 5-HT synthetic rate was slightly reduced with a sudden increase early in the attack, especially in the dorsal brainstem, to levels of control subjects: sumatriptan promptly reduced the 5-HT synthesis to lower values than those measured interictally, independently from changes in pain intensity. No side effects appeared at any stage. No differences were found between controls and migraine subjects during the attack or interictally, even in the last case, a slightly non significant reduction was found [92]. The same study group shows that female migraine patients exhibit lower 5-HT synthesis than female controls [93]. As reported above, the reduced habituation of cortical auditory and visually evoked potential in migraineurs interictally is considered the most characterizing marker of migraine patients, hypothesized due to a reduced preactivation level of sensory cortices due to low 5-HT neurostransmission [58-62]. These PET findings support this interpretation, that is 5-HT availability is decreased in the raphe-cortical serotonergic pathway. Also the normalization of habituation deficit just before and during the attack is in agreement with the increase of brain 5-HT synthetic rate, and especially in the dorsal brainstem during attack.

However, from the numerous studies focused on genetic alteration of 5-HT gene in migraine, there is no clear evidence for 5-HT transporter polymorphisms associated with migraine without aura $[7,8]$.

\section{Conclusions}

Numerous studies on platelet/plasma levels of 5-HT, as a mirror of synapse of central 5-HT neurons, have led, in the greater number of cases, to findings not showing a hyposerotonergic status in migraine and tension headache [1]. However, since most plasma/platelet 5-HT derive from the gut, it is unlikely an index of brain 5-HT levels if there is no particular genetic polymorphism of 5-HT metabolism (concerning the reuptake, biosynthesis, receptors, etc.) characterizing migraine subjects, so far not evidenced $[7,8]$.

Some interesting aspects emerge from studies on 5-HT vascular reactivity in migraine subjects: (1) an higher sensibility, especially in women, in comparison to controls (2) a reduced tachyphylaxis (habituation) successively evidenced as the more characteristic abnormality of cortical evoked potentials and ascribed to low 5-HT neurotransmission, (3) a lesser 5-HT vascular reactivity in the summer, when some studies show a lower incidence of migraine. These peripheral findings could be in agreement with a possible central hyposerotonergic status with consequent postsynaptic receptoral supersensitivity, more evident in women, and less in the summer.

The evidence of a possible alteration of brain 5-HT neurotransmission was possible through the evaluation of the effects of 5-HT agonists and of late with neuroimaging studies. It was rather evident that 5-HT releasers provoke headache both in migraine and controls, even if migraine patients are generally more vulnerable [6]. The possible mechanisms of these drugs are mainly two in number: (1) a neuronal and thereafter extraneuronal 5-HT depletion, consequent to 5-HT massive neuronal release and synaptic metabolization, of 5-HT descending pain inhibitory neurons of the brainstem, as previously suggested [65], (2) a direct (or indirect through 5-HT release) action on postsynaptic receptors. The first mechanism clash with animal evidences showing that $\mathrm{mCPP}$ and fenfluramine do not deplete brain 5-HT [80], and that RTD which diminished brain 5-HT synthesis does not provoke migraine attack [25, 89]. The last mechanism could explain the induction of migraine attack only through pain facilitating descending neurons which impact on trigeminal dorsal horn nociceptive neurons. In fact, both descending inhibitory and facilitatory effects of 5-HT on nociceptive transmission system from the brainstem are described $[94,95]$. On the other hand, there is no direct anatomical connection between 5-HT raphe neurons and meningeal blood vessels. These neurons innervate cortical microvessels [96], which, 
however, are lacking of sensory innervation [97]. Neuroimaging studies show that sumatriptan given during migraine attack reduces 5-HT synthetic brain activity, independently from pain relief, suggesting both a central action of triptans, and that this mechanism is not involved in therapeutic activity [92].

Some well-known trigger factors have been shown to provoke 5-HT release. Acute alcohol intake increases 5-HT release in the animal brain and in the platelets, and also a biphasic effect, that is an initial facilitation of 5-HT activity followed by a decrease several hours later, was reported $[98,99]$. Estrogens increase 5-HT neurotransmission and release (see [42]). Biochemical studies have clearly shown that 5-HT is a stress-responsive system with increase in 5-HT turnover during both acute and longer term stress $[5,100]$. The observation that migraine appearing in the perimenstrual period, in the relaxation period after prolonged stress (weekend headache), after acute stress (intense emotion/fear), or several hours after alcohol intake, can share a previous period characterized by increased 5-HT neurotransmission/release, which mime the action of 5-HT releaser drugs, is particularly intriguing.

Sicuteri's 5-HT central theory stated that migraine pain originates from an alteration, apparently functional in nature, of the neuraxial pain transmission. Pain arises without any stimulation of nociceptors, but result from an automatism of the nociceptive system, due to a failure of anti-nociceptive 5-HT system [3]. According to a subsequent theory called "functional deafferentation" [101], it was argued that migraine is a sub-cortical system failure of sensory modulatory networks that resulted in an enhanced delivery to the conscious level of normal neuronal signals such that they are perceived as abnormal [102]. Imaging studies pointed that brainstem being specific for migraine pathophysiology [90] and that migraine is a disorder associated of low central 5-HT disposition associated with an increase in 5-HT release during attack [7, 92].

On the other hand, some observations are not in accordance with a peripheral genesis of migraine pain (neurogenic inflammation):

1) Intracranial dura is innervated by neurons that exhibit properties characteristic of nociceptors in other tissues, and sumatriptan has no inhibitory effect on the discharge of dural nociceptors, either in the basal condition or after sensitization with inflammatory mediators. Also calcitonin gene-related peptides (CGRP) have no effect on the discharge of dural nociceptors [97]. Instead sumatriptan itself produced a transient discharge of these neurons which might underlie the initial worsening of headache [97, 103] that has been reported after sumatriptan administration and ergot derivatives [6]. In fact not only subcutaneous sumatriptan, but also small intravenous doses of sumatriptan $(500 \mu \mathrm{g})$, or of ergotamine $(50 \mu \mathrm{g})$, increase or provoke transitory, but sometimes longlasting, headache [104-106]. Interestingly, ergotamine $(50 \mu \mathrm{g})$, given to two migraine patients with mild headache provoked after 2-3 min, concomitantly with the start of hand vein contraction, a strong increase of headache and nausea which was still present after $30 \mathrm{~min}$ and subsided after intramuscular diclofenac, despite the persistence of a pronounced venoconstriction (104). This initial worsening of headache was suggested to be due to transitory high blood, and perhaps cerebral, drug levels [6, 106].

2) The $5-\mathrm{HT}_{1 \mathrm{D}}$ receptors are equally distributed in cranial afferents of the trigeminal system and in dorsal root ganglion afferents, and then triptans should regulate not only headache-associated pain, but also nociceptive response in extracranial tissues; but this is not the case [107].

3) Many 5-HT agonists, which potently inhibit neurogenic inflammation were ineffective in migraine treatment [108].

Therefore, the original theory of migraine as a deficit of central serotonergic antinociceptive system [3] is today perhaps the more explicit, as maintained by other researchers [7, 102].

Conflict of interest None.

\section{References}

1. Panconesi A (1995) 5-Hydroxytryptamine parameters in the periphery: how useful are they in the study of headaches? J Serotonin Res 2:117-137

2. Sicuteri F, Testi A, Anselmi B (1961) Biochemical investigations in headache: increase in the hydroxyndoleacetic acid excretion during migraine attacks. Int Arch Allergy Appl Immunol 19:55-58

3. Sicuteri F (1972) Headache as possible expression of deficiency of brain 5-hydroxytryptamine (central denervation supersensitivity). Headache 12:69-72

4. Sicuteri F (1976) Hypothesis: migraine, a central biochemical dysnociception. Headache 16:145-159

5. Jans LAW, Riedel WJ, Markus CR, Blokland A (2007) Serotonergic vulnerability and depression: assumptions, experimental evidence and implications. Mol Psychiatry 12:522-543

6. Panconesi A, Sicuteri R (1997) Headache induced by serotonergic agonists-a key to the interpretation of migraine pathogenesis? Cephalalgia 17:3-14

7. Hamel E (2007) Serotonin and migraine: biology and clinical implications. Cephalalgia 27:1295-1300

8. Montagna P (2008) The primary headaches: genetics, epigenetics and behavioural genetic model. J Headache Pain 9:57-69

9. Uebelhack R, Franke L, Herold N, Plotkin M, Amthauer H, Felix R (2006) Brain and platelet serotonin transporter in 
humans-correlation between [123I]-ADAM SPECT and serotonergic measurements in platelets. Neurosci Lett 406:153158

10. Ferrari MD, Saxena PR (1993) On serotonin and migraine: a clinical and pharmacological review. Cephalalgia 13:151-165

11. Waldenlinden E, Ross SB, Saaf J, Ekbom K, Wetterberg L (1985) Concentration and uptake of 5-hydroxytryptamine in platelets from cluster headache and migraine patients. Cephalalgia 5:45-54

12. Shukla R, Shanker K, Nag D, Verma M, Bhargava KP (1987) Serotonin in tension headache. J Neurol Neurosurg Psychiatry 50:1682-1684

13. Takeshima T, Shimomura T, Takahashi K (1987) Platelet activation in muscle contraction headache and migraine. Cephalalgia 7:239-243

14. Anthony M, Lance JW (1989) Plasma serotonin in patients with chronic tension headaches. J Neurol Neurosurg Psychiatry 52:182-184

15. Ferrari MD, Odink J, Tapparelli C, Van Kempen GMJ, Pennings EJM, Bruyn GW (1989) Serotonin metabolism in migraine. Neurology 39:1239-1242

16. Nakano T, Shimomura T, Takahashi K, Ikawa S (1993) Platelet substance $\mathrm{P}$ and 5-hydroxytryptamine in migraine and tensiontype headache. Headache 33:528-532

17. D'Andrea G, Hasselmark L, Alecci M, Cananzi A, Perini F, Welch KM (1994) Platelet secretion from dense and alphagranules in vitro in migraine with or without aura. J Neurol Neurosurg Psychiatry 57:557-561

18. D’Andrea G, Cananzi AR, Perini F, Hasselmark L (1995) Platelets models and their possible usefulness in the study of migraine pathogenesis. Cephalalgia 15:265-271

19. Kitano A, Shimomura T, Takeshima T, Takahashi K (1994) Increased 11-dehydrothromboxane B2 in migraine: platelet hyperfunction in patients with migraine during headache-free period. Headache 34:515-518

20. Srikiatkhachorn A, Anthony M (1996) Platelet serotonin in patients with analgesic-induced headache. Cephalalgia 16:423426

21. Stronks DL, Tulen JH, Verheij R, Boomsma F, Fekkes D, Pepplinkhuizen L, Mantel GW, Passchier J (1998) Serotonergic, cathecolaminergic, and cardiovascular reactions to mental stress in female migraine patients. A controlled study. Headache 38:270-280

22. Evers S, Quibeldey F, Grotemeyer K-H, Suhr B, Husstedt I-W (1999) Dynamic changes of cognitive habituation and serotonin metabolism during the migraine interval. Cephalalgia 19:485491

23. Jerney B, Vladic A, Cicin-Sain L, Hranilovic D, Banovic M, Balija M, Bilic E, Sucic Z, Vukadin S, Grgicevic D (2002) Platelet serotonin measures in migraine. Headache 42:588-595

24. Juhasz G, Zsombok T, Laszik A, Jakus R, Faludi G, Sotonyi P, Bagdy G (2003) Despite the general correlation of the serotonin transporter gene regulatory region polymorphism (5-HTTLPR) and platelet serotonin concentration, lower platelet serotonin concentration in migraine patients is independent of the 5HTTLPR variants. Neurosci Lett 350:56-60

25. Drummond PD (2005) Effect of tryptophan depletion on symptoms of motion sickness in migraineurs. Neurology 65:620-622

26. Bendtsen L, Mellerup ET (1998) The platelet serotonin transporter in primary headaches. Eur J Neurol 5:277-282

27. Juhasz G, Zsombok T, Modos EA, Olajos S, Jakab B, Nemeth J, Szolcsanyi J, Vitrai J, Bagdy G (2003) NO-induced migraine attack: strong increase in plasma calcitonin gene-related peptide (CGRP) concentration and negative correlation with platelet serotonin release. Pain 106:461-470
28. Rolf LH, Wiele G, Brune GG (1981) 5-Hydroxytryptamine in platelets of patients with muscle contraction headache. Headache 21:10-11

29. Shimomura T, Takahashi K (1990) Alteration of platelet serotonin in patients with chronic tension-type headache during cold pressor test. Headache 30:581-583

30. Leira R, Castillo J, Martinez F, Prieto JM, Noya M (1993) Platelet-rich plasma serotonin levels in tension-type headache and depression. Cephalalgia 13:346-348

31. Jensen R, Hindberg I (1994) Plasma serotonin increase during episodes of tension-type headache. Cephalalgia 14:219-222

32. D'Andrea G, Hasselmark L, Cananzi AR, Alecci M, Perini F, Zamberlan F, Welch KMA (1995) Metabolism and menstrual cycle rhythmicity of serotonin in primary headache. Headache 35:216-221

33. Mazzotta G, Sarchielli P, Gaggioli A, Gallai V (1997) Study of pressure pain and cellular concentration of neurotransmitters related to nociception in episodic tension-type headache patients. Headache 37:565-571

34. Bendtsen L, Jensen R, Hindberg I, Gammeltoft S, Olesen J (1997) Serotonin metabolism in chronic tension-type headache. Cephalalgia 17:843-848

35. Sarchielli P, Alberti A, Russo S, Codini M, Panico R, Floridi A, Gallai V (1999) Nitric oxide pathway, $\mathrm{Ca}^{2+}$, and serotonin content in platelets from patients suffering from chronic daily headache. Cephalalgia 19:810-816

36. Rossi C, Pini LA, Cupini ML, Calabresi P, Sarchielli P (2008) Endocannabinoids in platelets of chronic migraine patients and medication-overuse headache patients: relation with serotonin levels. Eur J Clin Pharmacol 64:1-8

37. Panconesi A, Anselmi B, Curradi C, Del Bianco PL, Franchi G, Sicuteri F, Tarquini B (1986) Biological rhythms of vascular reactivity to serotonin in man. In: Halberg F, Reale L, Tarquini $\mathrm{B}$ (eds) Proceedings of the II international symposium on chronobiologic approach to social medicine. Istituto Italiano di Medicina Sociale, Rome, pp 701-714

38. Dignan RJ, Yeh T Jr, Dike CM, Lutz HAIII, Wechsler AS (1992) The influence of age and sex on human internal mammary artery size and reactivity. Ann Thorac Surg 53:792-797

39. Mong K, Duggan JA, Tabrizchi R (2002) Comparative study of functional responses and morphometric state of distal radial arteries in male and female. Ann Thorac Surg 74:2126-2131

40. Weiss LA, Abney M, Cook EH Jr, Ober C (2005) Sex-specific genetic architecture of blood serotonin levels. Am J Hum Genet 76:33-41

41. Cosgrove KP, Mazure CM, Staley JK (2007) Evolving knowledge of sex differences in brain structure, function, and chemistry. Biol Psychiatry 62:847-855

42. Sakai Y, Nishikawa M, Leyton M, Benkelfat C, Young SN, Diksic M (2006) Cortical trapping of $\alpha-\left[{ }^{11} \mathrm{C}\right]$ methyl-L-tryptophan, an index of serotonin synthesis, is lower in females than males. NeuroImage 33:815-824

43. Heninger GR (1997) Serotonin, sex, and psychiatric illness. Proc Natl Acad Sci 94:4823-4824

44. Nishizava S, Benkelfat C, Young SN, Leyton M, Mzengeza S, de Montigny C, Blier P, Diksic M (1997) Differences between males and females in rates of serotonin synthesis in human brain. Proc Natl Acad Sci 94:5308-5313

45. Chugani DC, Muzik O, Chakraborty P, Magner T, Chugani HT (1998) Human brain serotonin synthesis capacity measured in vivo with alpha-[C-11]methyl-L-tryptophan. Synapse 28:33-43

46. Centeno ML, Reddy AP, Smith LJ, Sanchez RL, Henderson JA, Salli NC, Hess DJ, Pau FKY, Bethea CL (2007) Serotonin in microdialysate from mediobasal hypothalamus increases after progesterone administration to estrogen primed macaques. Eur J Pharmacol 555:67-75 
47. Marrelli A, Marini C, Prencipe M (1988) Seasonal and meteorological factors in primary headaches. Headache 28:111-113

48. Cugini P, Romit A, Di Palma L, Giacovazzo M (1990) Common migraine as a weekly and seasonal headache. Chronobiol Int 7:467-469

49. Robbins L (1994) Precipitating factors in migraine: a retrospective review of 494 patients. Headache 34:214-216

50. Fox AW, Davis RL (1998) Migraine chronobiology. Headache 38:436-441

51. Rieder A, Lobentanz I, Zeitlhofer J, Mitsche N, Lawrence K, Schwarz B, Kunze M (2004) Background morbidity of headache in an adult general population. Results of the Austrian SERMO (self-reported morbidity) study. Wien Klin Wochenschr 116:176-181

52. Soriani S, Fiumana E, Manfredini R, Boari B, Battistella PA, Canetta E, Pedretti S, Borgna-Pignatti C (2006) Circadian and seasonal variation of migraine attacks in children. Headache 46:1571-1574

53. Alstadhaug KB, Bekkelund S, Salvesen R (2007) Circannual periodicity of migraine? Eur J Neurol 14:983-988

54. Brewerton TD (1989) Seasonal variation of serotonin function in humans: research and clinical implications. Ann Clin Psychiatry $1: 153-164$

55. Lambert GW, Reid C, Kaye DM, Jennings GL, Esler MD (2002) Effect of sunlight and season on serotonin turnover in the brain. Lancet 360:1840-1842

56. Neumeister A, Pirker W, Willeit M, Praschak-Rieder N, Asenbaum S, Brucke T, Kasper S (2000) Seasonal variation in availability of serotonin transporter binding sites in healthy female subjects as measured by $\left[{ }^{123} \mathrm{I}\right]-2 \beta$-carbomethoxy- $3 \beta$-(4iodophenyl)tropane and single photon emission computed tomography. Biol Psichiatry 47:158-160

57. Sicuteri F, Panconesi A, Franchi G, Del Bianco PL, Anselmi B (1983) Impaired 5-hydroxytryptamine tachyphylaxis in migraine. Cephalalgia 3:139-142

58. Hegerl U, Juckel G (1993) Intensity dependence of auditory evoked potentials as an indicator of central serotonergic neurotransmission: a new hypothesis. Biol Psychiatr 33:173-187

59. Ambrosini A, de Noordhout AM, Sandor PS, Schoenen J (2003) Electrophysiological studies in migraine: a comprehensive review of their interest and limitations. Cephalalgia 23(Suppl 1):13-31

60. Ambrosini A, Rossi P, De Pasqua V, Pierelli F, Schoenen J (2003) Lack of habituation causes high intensity dependance of auditory evoked cortical potentials in migraine. Brain 126:20092015

61. Magis D, Ambrosini A, Bendtsen L, Ertas M, Kaube H, Schoenen J (EUROHEAD project) (2007) Evaluation and proposal for optimalization of neurophysiological tests in migraine: part 1-electrophysiological tests. Cephalalgia 27:1323-1338

62. Coppola G, Ambrosini A, Di Clemente L, Magis D, Fumal A, Gerard P, Pierelli F, Schoenen J (2007) Interictal abnormalities of gamma band activity in visual evoked responses in migraine: an indication of thalamocortical dysrhythmia? Cephalalgia 27:1360-1367

63. Judit A, Sandor PS, Schoenen J (2000) Habituation of visual and intensity dependence of auditory evoked cortical potentials tends to normalize just before and during the migraine attack. Cephalalgia 20:714-719

64. Kropp P, Gerber W-D (1995) Contingent negative variation during migraine attack and interval: evidence for normalization of slow cortical potentials during the attack. Cephalalgia 15:123-128

65. Sicuteri F, Poggioni M, Panconesi A (1990) Upregulation of pain transmission from deficient serotonergic analgesia in migraine. In: Paoletti R, Vanhoutte PM, Brunello N, Maggi FM (eds) Serotonin: from cell biology to pharmacology and therapeutics. Kluwer, Dordrecht, pp 391-404

66. Huber D, Henrich G, Gundel H (2005) Psychophysiological response patterns of migraine patients in two habituation tests. Headache 45:1375-1387

67. Ozkul Y, Ay H (2007) Habituation of sympathetic skin response in migraine and tension type headache. Auton Neurosci 134:8184

68. Iversen HK, Olesen J (1993) Experimental headache. In: Olesen J, Tfelt-Hansen P, Welch KMA (eds) The headaches. Raven Press, New York, pp 145-151

69. Del Bene E, Anselmi B, Del Bianco PL, Fanciullacci M, Galli P, Salmon S, Sicuteri F (1997) Fenfluramine headache: a biochemical and monoamine receptorial human study. In: Sicuteri F (ed) Headache: new vistas. Biomedical Press, Florence, pp 101109

70. Sicuteri F (1971) Pain syndrome in man following treatment with p-chlorophenylalanine. Pharmacol Res Comm 3:401-407

71. Nattero G, Lisino F, Brandi G, Gastaldi L (1976) Reserpine in the prevention of migraine and in the therapy of tension-vascular headache. Minerva Med 67:1871-1875

72. Muldoon MF, Manuck SB, Jansma CL, Moore AL, Perel J, Mann JJ (1996) D, L-Fenfluramine challenge test: experience in nonpatient sample. Biol Psychiatry 39:761-768

73. Brewerton TD, Murphy DL, Mueller EA, Jimerson DC (1988) Induction of migraine-like headaches by the serotonin agonist m-chlorophenylpiperazine. Clin Pharmacol Ther 43:605-609

74. Brewerton TD, Murphy DL, Lesem MD, Brandt HA, Jimerson DC (1992) Headache responses following m-chlorophenylpiperazine in bulimics and controls. Headache 32:217-222

75. Gordon ML, Lipton RB, Brown S-L, Nakraseive C, Russell M, Pollack SZ, Korn ML, Merriam A, Solomon S, van Praag HM (1993) Headache and cortisol responses to m-chlorophenylpiperazine are highly correlated. Cephalalgia 13:400-405

76. Gijsman HJ, van Gerven JMA, Tieleman MC, Schoemaker RC, Pieters MSM, Ferrari MD, Cohen AF, van Kempen GMJ (1988) Pharmacokinetic and pharmacodynamic profile of oral and intravenous meta-chlorophenylpiperazine in healthy volunteers. J Clin Psychopharmacol 18:289-295

77. Leone M, Attanasio A, Croci D, Filippini G, D’Amico D, Grazzi L, Nespolo A, Bussone G (2000) The serotonergic agent mchlorophenylpiperazine induces migraine attacks: a controlled study. Neurology 55:136-139

78. Feuchtl A, Bagli M, Stephan R, Frahnert C, Kolsch H, Kuhn KU, Rao ML (2004) Pharmacokinetics of m-chlorophenylpiperazine after intravenous and oral administration in healthy male volunteers: implication for the pharmacodynamic profile. Pharmacopsychiatry 37:180-188

79. Leone M, Attanasio A, Croci D, Ferraris A, D'Amico D, Grazzi L, Nespolo MA, Bussone G (1988) 5-HT ${ }^{1 \mathrm{~A}}$ receptor hypersensitivity in migraine is suggested by the $\mathrm{m}$-chlorophenylpiperazine test. Neuroreport 9:2605-2608

80. Rothman RB, Baumann MH (2002) Serotonin re leasing agents. Neurochemical, therapeutic and adverse effects. Pharmacol Biochem Behav 71:825-836

81. Baylen CA, Rosemberg H (2006) A review of the acute subjective effects of MDMA/ectasy. Addiction 101:933-947

82. Moja PL, Cusi C, Sterzi RR, Canepari C (2007) Selective serotonin re-uptake inhibitors (SSRIs) for preventing migraine and tension-type headache. The Cochrane Library 4:1-50

83. Tomkins GE, Jackson JL, O'Malley PG, Balden E, Santoro JE (2001) Treatment of chronic headache with antidepressant: a meta-analysis. Am J Med 111:54-63

84. Ashina S, Bendtsen L, Jensen R (2004) Analgesic effect of amitriptyline in chronic tension-type headache is not directly related to serotonin reuptake inhibition. Pain 108:108-114 
85. Hoyer D, Clarke DE, Fozard JR, Hartig PR, Martin GR, Mylecharane EJ, Saxena PR, Humphrey PP (1994) International union of pharmacology classification of receptors for 5hydroxytryptamine (serotonin). Pharmacol Rev 46:157-203

86. Moore P, Landolt H-P, Seifritz E, Clark C, Bhatti T, Kelsoe J, Rapaport M, Gillin JC (2000) Clinical and physiological consequences of rapid tryptophan depletion. Neuropsychopharmacology 23:601-622

87. Van der Plasse G, Meerkerk DJ, Lieben CKJ, Blokland A, Feenstra MGP (2007) Lack of evidence for reduced prefrontal cortical serotonin and dopamine efflux after acute tryptophan depletion. Psychopharmacology 195:377-385

88. Fusar-Poli P, Allen P, McGuire P, Placentino A, Cortesi M, Perez J (2006) Neuroimaging and electrophysiological studies of the effects of acute tryptophan depletion: a systematic review of the literature. Psychopharmacology 188:131-143

89. Drummond PD (2006) Tryptophan depletion increases nausea, headache and photophobia in migraine sufferers. Cephalalgia 26:1225-1233

90. Schuh-Hofer S, Richter M, Geworski L, Villringer A, Israel H, Wenzel R, Munz DL, Arnold G (2007) Increased serotonin transporter availability in the brainstem of migraineurs. J Neurol 254:789-796

91. Chugani DC, Niimura K, Chaturvedi S, Muzik O, Fakkouri M, Lee ML, Chugani HT (1999) Increased brain serotonin synthesis in migraine. Neurology 53:1473-1479

92. Sakai Y, Dobson C, Diksic M, Aubè M, Hamel E (2008) Sumatriptan normalizes the migraine attack-related increase in brain serotonin synthesis. Neurology 70:431-439

93. Diksic M, Sakai Y, Nishikawa M, Hamel E, Aubé M (2008) Female migraine patients exhibit lower brain serotonin (5-HT) synthesis interictally than female controls. Cephalalgia 28:440 (abstract)

94. Yoshimura M, Furue H (2006) Mechanisms for the anti-nociceptive actions of the descending noradrenergic and serotonergic systems in the spinal cord. J Pharmacol Sci 101:107-117

95. Sommer C (2006) Is serotonin hyperalgesic or analgesic? Curr Pain Head Rep 10:101-106
96. Hamel E (2006) Perivascular nerves and the regulation of cerebrovascular tone. J Appl Physiol 100:1059-1065

97. Strassman AM, Levy D (2006) Response properties of dural nociceptors in relation to headache. J Neurophysiol 95:12981306

98. LeMarquand D, Pihl RO, Benkelfat C (1994) Serotonin and alcohol intake, abuse, and dependence: findings of animal studies. Biol Psichiatry 36:395-421

99. Panconesi A (2008) Alcohol and migraine: trigger factor, consumption, mechanisms. A review. J Headache Pain 9:71-76

100. Flugge G, van Kampen M, Mijnster MJ (2004) Perturbations in brain monoamine systems during stress. Cell Tissue Res 315:114

101. Sicuteri F (1987) Quasi-phantom head pain from functional deafferentation. Clin J Pain 3:63-80

102. Lance JW, Goadsby PJ (2005) Mechanism and management of Headache, 7th edn. Elsevier, New York

103. Burnstein R, Jakubowski M, Levy D (2005) Anti-migraine. action of triptans is preceded by transient aggravation of headache caused by activation of meningeal nociceptors. Pain 115:21-22

104. Panconesi A (1994) Azione vasocostrittiva del sumatriptan nei vasi periferici dell'uomo. Confin Cephalal 3:5-12

105. Panconesi A, Franchi G, Anselmi B, Curradi C, Tarquini B (1993) Amplifying effect of sumatriptan on noradrenaline venoconstriction in migraine patients. Cephalalgia 13:383-388

106. Panconesi A, Franchi G, Anselmi B, Curradi C (1994) On the mechanism of sumatriptan side effects. In: Fusco BM, Giacovazzo $M$ (eds) Unilateral headache: focus on recent advances. RD Editori, Rome, pp 111-116

107. Potrebic S, Ahn AH, Skinner K, Fields HL, Basbaum AI (2003) Peptidergic nociceptors of both trigeminal and dorsal root ganglia express serotonin 1D receptors: implications for the selective antimigraine action of triptans. J Neurosci 23:10988-10997

108. Villalon CM, Centurion D (2007) Cardiovascular responses produced by 5-hydroxytryptamine: a pharmacological update on the receptors/mechanisms involved and therapeutic implication. Naunyn Schmiedebergs Arch Pharmacol 376:45-63 